\section{Temperature responsive polymer brushes with clicked rhodamine B: synthesis, characterization and swelling dynamics studied by spectroscopic ellipsometry $\dagger$}

\author{
Sebastian Rauch, ${ }^{a b}$ Klaus-Jochen Eichhorn, ${ }^{a}$ Ulrich Oertel, ${ }^{a}$ Manfred Stamm, ${ }^{a b}$ Dirk Kuckling ${ }^{c}$ \\ and Petra Uhlmann*a
}

Received 6th July 2012, Accepted 2nd August 2012

DOI: 10.1039/c2sm26571k

Here, we report on a new temperature responsive polymer brush system with a terminal "click" functionality. Bifunctionalized poly ( $N$-isopropylacrylamide) (PNiPAAm) with distinct functional end groups was synthesized by atom transfer radical polymerization (ATRP) and grafted to a modified silicon substrate. The presence of the active terminal alkyne functionality is validated using an azidemodified rhodamine B (N3-RhB) via copper(I) catalyzed alkyne-azide cycloaddition (CuAAC). The optical properties and swelling dynamics of an N3-RhB modified PNiPAAm brush are analyzed in dry state and in situ by VIS-spectroscopic ellipsometry (SE). The best-fit results are obtained using a Gaussian oscillator model and are confirmed by UV/VIS-spectroscopy. We observed evidence of interactions between the aromatic residues of the dye and the PNiPAAm amide groups, which significantly affect the swelling behavior of the modified polymer brush.

\section{Introduction}

Stimuli-responsive polymers are promising materials for the development of smart surfaces that can change their properties in response to environmental stimuli. Since the type and rate of the response to external stimuli can be regulated by chain length, composition, architecture, and topology, polymers offer a variety of opportunities to design such stimuli-responsive surfaces. $^{1-3}$ The water-soluble poly $(N$-isopropylacrylamide $)$ (PNiPAAm) is one of the best studied environmentally responsive polymers with a temperature-sensitive phase transition in aqueous solution possessing a lower critical solution temperature (LCST) of $c a .31{ }^{\circ} \mathrm{C}^{4-6}$ This transition is referred to as a coil-toglobule transition and has been attributed to changes in the hydrogen bonding properties of water. ${ }^{7-11}$ As the LCST is not far from physiological temperatures and can be considerably increased by copolymerization, ${ }^{12-14}$ this polymer is appealing for biomedical purposes. In recent years, PNiPAAm thin films have been investigated for various applications such as the control of protein adsorption, cell adhesion, ${ }^{15-17}$ formation of chemical gates, ${ }^{18-20}$ tunable adhesion of biomolecules, ${ }^{21,22}$ passive flow control in microcapillaries, ${ }^{23}$ and in conjunction with immobilized nanoparticles for sensor developments. ${ }^{24}$ Well-defined

${ }^{a}$ Leibniz-Institut für Polymerforschung Dresden e.V., 01069 Dresden, Germany.E-mail: uhlmannp@ipfdd.de

${ }^{b}$ Physical Chemistry of Polymer Materials, Technische Universität Dresden, 01062 Dresden, Germany

'Department of Chemistry, University of Paderborn, 33098 Paderborn, Germany

$\dagger$ Electronic supplementary information (ESI) available. See DOI: $10.1039 / \mathrm{c} 2 \mathrm{sm} 26571 \mathrm{k}$ brush films are especially promising for the design of proteinresistant, temperature-sensitive interfaces for use in sensor applications. ${ }^{25,26}$

For the synthesis of well-defined polymers and macromolecular architectures, atom transfer radical polymerization (ATRP) is one of the most studied controlled radical polymerization techniques. ${ }^{27-29}$ It allows the preparation of a wide range of polymers with precise control over molecular weight, molecular weight distribution, and chain functionality. Typically ATRP is conducted in homogeneous media such as bulk or organic solvents. For hydrophilic, ionic, and water-soluble monomers, like $N$-isopropylacrylamide (NiPAAm), a continuous effort was made to establish ATRP in aqueous media. ${ }^{30-33}$

Through the use of functional monomers or initiators and postpolymerization modification reactions, it is possible to synthesize a variety of functionalized polymers. ${ }^{34}$ One recently introduced method for installing functionality onto materials is so-called "click" chemistry, which is an appealing concept proposed by Sharpless and co-workers. ${ }^{35}$ Copper-catalyzed azide-alkyne cycloaddition (CuAAC) yielding disubstituted $[1,2,3]$-triazoles is characterized by near-quantitative yields, regiospecific conversions, and compatibility with a broad range of functional groups and reaction conditions. ${ }^{35}$ Although click chemistry was initially postulated as a general concept for organic synthesis, this strategy also has an enormous potential in materials science ${ }^{36-38}$ and has been used for the preparation of crosslinked networks and for the functionalization of both polymers in solution ${ }^{39-41}$ and polymeric coatings on surfaces. ${ }^{42-44}$ Click chemistry has furthermore played a major role in the development of polymer-based bioconjugates, ${ }^{45,46}$ with potential applications in the areas of biology and biomedicine. ${ }^{47}$ 
PNiPAAm brushes with low polydispersity were prepared successfully by "grafting-to" of preformed end functionalized chains to a reactive surface, ${ }^{25}$ and by "grafting-from" using surface-initiated ATRP. ${ }^{26,48,49}$ The swelling behavior of PNiPAAm brushes made by "grafting from" was studied with a variety of methods including neutron reflectometry, ${ }^{48,50}$ contact angle measurements, ${ }^{26}$ surface plasmon resonance, ${ }^{51}$ ellipsometry, ${ }^{1}$ and atomic force microscopy (AFM) ${ }^{52}$ However, to our knowledge, there exist only a few detailed studies on the temperature sensitivity of PNIPAAm "grafting-to" brushes. ${ }^{53-55}$ In our recent work ${ }^{1}$ the physicochemical properties of PNiPAAm brushes ("grafting to") with different molecular weights $\left(M_{\mathrm{n}}\right)$ and grafting densities $(\sigma)$ were investigated. These brushes are prepared with well-defined preformed polymer chains that can be designed and functionalized according to the needs of applications before grafting.

Thus we were motivated to combine the interesting stimuliresponsive properties of PNiPAAm brushes with the enormous modification potential of "click" chemistry to design smart surfaces with broad application possibilities, like sensor systems for controlled bioadhesion. First, we report on the synthesis and characterization of bi-functionalized PNiPAAm via ATRP with one chain end used for the "grafting to" approach while the other free end remains active for postmodification reactions via "click" chemistry. Second, we analyze the "grafting to" behaviour and test the activity of the free alkyne chains of the as-prepared polymer brushes for postmodification reactions via CuAAC reaction. For this purpose an azide-modified rhodamine dye was synthesized and attached to the free chain ends. The physicochemical properties of the resulting rhodamine dye modified PNiPAAm brushes were examined for the first time with VISspectroscopic ellipsometry (SE) in the dry state and in situ and confirmed by UV/VIS measurements.

\section{Experimental section}

\section{Materials}

$N$-Isopropylacrylamide (97\%), copper(I) chloride ( $\mathrm{CuCl}, \geq 99 \%)$, tert-butyl $\alpha$-bromoisobutyrate ( $t \mathrm{BBiB}, \geq 98 \%$ ), copper(II) sulfate pentahydrate $\left(\mathrm{CuSO}_{4} \cdot 5 \mathrm{H}_{2} \mathrm{O}, 99.995 \%\right)$, L-ascorbic acid (L-Asc, $99 \%$ ), tetrabutylammonium fluoride (TBAF, $1.0 \mathrm{M}$ in THF), $N, N, N^{\prime}, N^{\prime}$-tetramethylethylenediamine (TMEDA, $\geq 99.5 \%$ ), deuterated dimethylsulfoxide (DMSO-d 6 , 99.9 atom\%), deuterated chloroform $\left(\mathrm{CDCl}_{3}, 99.69\right.$ atom $\left.\%\right)$ and $N, N^{\prime}$-dimethylformamide (DMF, $\geq 99.8 \%$ ) were purchased from SigmaAldrich. Tris[2-(dimethylamino)ethyl]amine ( $\left.\mathrm{Me}_{6} \mathrm{TREN}, 99 \%\right)$ was purchased from ABCR. Poly(glycidyl methacrylate) (PGMA, $17500 \mathrm{~g} \mathrm{~mol}^{-1}, M_{\mathrm{w}} / M_{\mathrm{n}}=1.7$ ) was purchased from Polymer Source, Inc. (Canada). Absolute ethanol (EtOH, $99.8 \%)$, diethyl ether $\left(\mathrm{Et}_{2} \mathrm{O}, \geq 99.8 \%\right)$, hexane $(\geq 99.0 \%)$, hydrogen peroxide $\left(\mathrm{H}_{2} \mathrm{O}_{2}, 33 \%\right)$ and aluminium oxide $90\left(\mathrm{Al}_{2} \mathrm{O}_{3}\right.$, active neutral, 70-230 mesh) were acquired from Merck. Tetrahydrofuran (THF, 99.98\%), chloroform $\left(\mathrm{CHCl}_{3}, 99 \%+\right)$ and ammonium hydroxide $\left(\mathrm{NH}_{4} \mathrm{OH}, 25 \%\right)$ were purchased from Acros Organics. Purified water $\left(\mathrm{H}_{2} \mathrm{O}\right)$ was used from a Milli-Q Direct 8 system from EMD Millipore Corporation.

The monomer was recrystallized three times from hexane prior to use. $\mathrm{CuCl}$ was purified by stirring with acetic acid overnight.
After filtration, it was washed with ethanol and ether and then dried in a vacuum oven. (Trimethylsilyl)propargyl acrylamide (TMS-PAAm) and rhodamine B azide (N3-RhB) were synthesized as described previously. ${ }^{56,57}$ All chemicals were used as received if not otherwise specifically noted. As sample substrates silicon wafers oriented in the [100] direction with about $1.6 \mathrm{~nm}$ native silicon dioxide obtained from Si-Mat (Kaufering, Germany) and fused silica plates were used.

\section{Synthesis of bifunctional poly( $N$-isopropylacrylamide)}

First a $0.1 \mathrm{M}$ stock solution of a $\mathrm{Cu}(\mathrm{I})-\mathrm{M}_{6} \mathrm{TREN}$ complex was prepared by placing $\mathrm{Cu}(\mathrm{I}) \mathrm{Cl}(51 \mathrm{mg}, 0.515 \mathrm{mmol})$ and $\mathrm{Me}_{6}$ TREN (123.6 $\mathrm{mg}, 0.531 \mathrm{mmol})$ in $5 \mathrm{~mL}$ DMF. The resulting dark green solution was then degassed by means of three consecutive "freeze-pump-thaw cycles". In a $15 \mathrm{~mL}$ Schlenk flask equipped with a silicone septum, NIPAAm $(2.2 \mathrm{~g}, 19.4 \mathrm{mmol})$ and $t \mathrm{BBiB}$ $(7.5 \mu \mathrm{L}, 0.039 \mathrm{mmol})$ were dissolved in $8.0 \mathrm{~mL}$ of $\mathrm{H}_{2} \mathrm{O}-\mathrm{DMF}$ $(1: 1, \mathrm{v} / \mathrm{v})$. The solution was degassed by means of three consecutive "freeze-pump-thaw cycles" and equilibrated in a water bath at $20^{\circ} \mathrm{C}$. The polymerization was initiated by adding $0.4 \mathrm{~mL}$ of the $\mathrm{Cu}(\mathrm{I})-\mathrm{Me}_{6}$ TREN stock solution to the mixture. After $98 \mathrm{~min} 0.5 \mathrm{~mL}$ of a degassed solution of TMS-PAAm (104 mg, $0.574 \mathrm{mmol}$ ) in DMF was rapidly injected. After $2.5 \mathrm{~h}$ the polymerization was quenched by abrupt freezing with liquid nitrogen followed by removal of the septum. The mixture was thawed and the solvent was removed under reduced pressure. For purification, the crude product was dissolved in THF and passed through an $\mathrm{Al}_{2} \mathrm{O}_{3}$ column to remove the copper complex. After removing the solvent under reduced pressure, the polymer was dissolved in a small amount of THF and precipitated in $\mathrm{Et}_{2} \mathrm{O}$ at $-50{ }^{\circ} \mathrm{C}$. Finally the precipitate was dried in a vacuum at $50{ }^{\circ} \mathrm{C}$ to yield a colorless pAlk-PNiPAAm (1.62 g, 74\%).

\section{TMS-deprotection of pAlk-PNiPAAm}

In a $50 \mathrm{~mL}$ round-bottom flask $500 \mathrm{mg}$ pAlk-PNiPAAm was dissolved in dry THF $(21 \mathrm{~mL})$, and the solution was cooled to $0{ }^{\circ} \mathrm{C}$. After addition of TBAF $(1.0 \mathrm{M}, 0.1 \mathrm{~mL})$ to the solution, the mixture was stirred at $0{ }^{\circ} \mathrm{C}$ for additional $2 \mathrm{~h}$. The solution was then concentrated under reduced pressure and the polymer was precipitated three times in $\mathrm{Et}_{2} \mathrm{O}$ at $0{ }^{\circ} \mathrm{C}$. The precipitate was dried in a vacuum at $50{ }^{\circ} \mathrm{C}$ to yield colorless Alk-PNiPAAm (390 mg, $78 \%)$.

\section{Preparation of polymer brushes}

Silicon $(\mathrm{Si}, 20 \times 13 \mathrm{~mm})$ or fused silica $(\mathrm{FS}, 43 \times 9 \mathrm{~mm})$ substrates were treated with $\mathrm{EtOH}$ in an ultrasonic bath for 15 min and dried with a stream of nitrogen. Afterwards they were exposed to a cleaning solution of $\mathrm{NH}_{4} \mathrm{OH}-\mathrm{H}_{2} \mathrm{O}_{2}-\mathrm{H}_{2} \mathrm{O}(1: 1: 6$, $\mathrm{v} / \mathrm{v} / \mathrm{v}$ ) at $70{ }^{\circ} \mathrm{C}$ for $20 \mathrm{~min}$, rinsed twice with $\mathrm{H}_{2} \mathrm{O}$ and dried with a stream of nitrogen. Next a thin layer of PGMA $(\sim 2 \mathrm{~nm})$ was deposited by spincoating (spin 150, SPS coating) a PGMA solution in $\mathrm{CHCl}_{3}\left(0.3 \mathrm{mg} \mathrm{mL}{ }^{-1}\right)$ with subsequent annealing at $100{ }^{\circ} \mathrm{C}$ in a vacuum oven for $20 \mathrm{~min}$ to react the silanol groups of the substrate with a fraction of the epoxy groups of PGMA, thus forming an anchoring layer equipped with the remaining epoxy groups for the following "grafting to" process. ${ }^{58}$ Afterwards, a filtered polymer solution in THF $\left(9 \mathrm{mg} \mathrm{mL}^{-1}\right)$ was spincoated 
onto the PGMA layer and annealed at $150^{\circ} \mathrm{C}$ in a vacuum oven for $15 \mathrm{~h}$. To remove noncovalently bonded polymer, the resulting films were first immersed in $\mathrm{H}_{2} \mathrm{O}$, then extracted in $\mathrm{H}_{2} \mathrm{O}$ overnight, rinsed with EtOH and dried in a stream of nitrogen.

\section{Functionalization of (p)Alk-PNiPAAm brushes with N3-RhB}

For the CuAAC reaction between (p)Alk-PNiPAAm brushes and N3-RhB stock solutions of N3-RhB (9 mM, Sl-1), $\mathrm{CuSO}_{4} \cdot 5 \mathrm{H}_{2} \mathrm{O}-\mathrm{TMEDA}(1: 5,7.5 \mathrm{mM}, \mathrm{Sl}-2)$ and L-Asc $(0.12 \mathrm{M}$, $\mathrm{Sl}-3)$ in $0.1 \mathrm{M}$ phosphate buffer $(\mathrm{pH} 6.6)$ were prepared. The modified silicon or fused silica substrates were placed in a sample holder immersed in $28 \mathrm{~mL}$ phosphate buffer. $0.4 \mathrm{~mL}$ of Sl-1 was added under stirring followed by $1 \mathrm{~mL}$ of Sl-2 and $1 \mathrm{~mL}$ of Sl-3. After the reaction was complete the samples were rinsed with water and stirred in $50 \mathrm{mM}$ EDTA to remove trace amounts of copper. The samples were again rinsed with $\mathrm{H}_{2} \mathrm{O}$ and several times with EtOH to remove unreacted N3-RhB adsorbed on the polymer brushes.

\section{Polymer characterization}

The determination of the molecular weight and molecular weight distribution was performed on an Agilent Technologies HP Agilent 1100 HPLC system equipped with an Agilent 1100 series refractive-index (RI) detector. $N, N$-Dimethylacetamide (DMAc) containing $2 \mathrm{vol} \% \mathrm{H}_{2} \mathrm{O}$ and $3 \mathrm{~g} \mathrm{~L}^{-1} \mathrm{LiCl}$ was used as an eluent in combination with two Zorbax PSM Trimodal-S columns. The calibration of this SEC analysis was performed with poly(methyl methacrylate) standards. The flow rate used was $0.5 \mathrm{~mL} \mathrm{~min}{ }^{-1}$. Further GPC measurements were carried out on a Polymer Laboratories PL-GPC 50 Plus Integrated GPC System equipped with a microvolume double piston pump purchased from Agilent Technologies. DMAc containing $3 \mathrm{~g} \mathrm{~L}^{-1} \mathrm{LiCl}$ was used as an

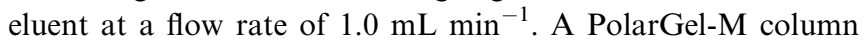
from Polymer Laboratories connected to a Mini DAWN light scattering (LS) detector from Wyatt Technology was applied.

${ }^{1} \mathrm{H}-\mathrm{NMR}$ spectra were recorded on a Bruker Avance III 500 NMR spectrometer operating at $500.13 \mathrm{MHz}$. The solvent signals were used as internal standard: DMSO- $\mathrm{d}_{6}: \delta\left({ }^{1} \mathrm{H}\right)=2.50$ ppm and $\mathrm{CDCl}_{3}: \delta\left({ }^{1} \mathrm{H}\right)=7.26 \mathrm{ppm}$, respectively.

Modulated DSC analysis was performed with a differential scanning calorimeter Q1000 purchased from TA Instruments (USA) in nitrogen atmosphere from $-30{ }^{\circ} \mathrm{C}$ to $+250{ }^{\circ} \mathrm{C}$ at a scan rate of $2 \mathrm{~K} \mathrm{~min}^{-1}$. A heating-cooling-heating cycle was carried out to realise a uniform thermal history. The data were calculated from the reversing heat flow signal of the second heating cycle. $T_{\mathrm{g}}$ values were determined using the half-step method.

\section{Ellipsometric measurements}

A spectroscopic ellipsometer (alpha-SE, Woollam Co., Inc., Lincoln NE, USA) equipped with a rotating compensator was used to measure the ellipsometric data $\Delta$ (relative phase shift) and $\tan \Psi$ (relative amplitude ratio) of the brush films in the dry state as well as in situ in purified $\mathrm{H}_{2} \mathrm{O}$ within a batch cuvette (TSL Spectrosil, Hellma, Muellheim, Germany). ${ }^{1,59}$ All measurements were performed between 370 and $900 \mathrm{~nm}$ at an angle of incidence $\Phi_{0}$ of $70^{\circ}$, which is close to the Brewster angle of silicon. All data were acquired and analyzed using CompleteEASE® software version 4.46. To evaluate the refractive index $n$, dry thickness $d$ and swollen thickness $h$ of the polymer brush, a multilayer-boxmodel consisting of silicon, silicon dioxide, anchoring layer PGMA, and a polymer brush was assumed. The dispersion relations for silicon and silicon oxide were taken from the software library and the refractive index of PGMA was set to $1.525 .^{60}$ For the pure nonabsorbing polymer brush layer, either a Cauchy relation $\left(n(\lambda)=A+B / \lambda^{2}\right)$ was used to describe the dependence of the refractive index on the wavelength, or, in the case of thin films below $10 \mathrm{~nm}$ thickness, the Cauchy parameter were fixed to $A=$ 1.485 and $B=0.00486$ because of a strong correlation between $n$ and $d$ in this region of film thickness. For polymer brushes functionalized with rhodamine B a Gaussian oscillator model with two oscillators was used to describe the complex dielectric constants $\varepsilon_{1}$ and $\varepsilon_{2}$ and thus the optical functions $n$ and $k$. Each oscillator is parametrized by the center peak energy $\left(E_{\mathrm{n}}\right)$, amplitude $\left(A_{\mathrm{n}}\right)$ and broadening $\left(\mathrm{Br}_{\mathrm{n}}\right)$ according to

$$
\varepsilon_{2}(E)=A_{\mathrm{n}}\left(\mathrm{e}^{-\left(\frac{E-E_{\mathrm{n}}}{\sigma}\right)^{2}}-\mathrm{e}^{-\left(\frac{E+E_{\mathrm{n}}}{\sigma}\right)^{2}}\right)
$$

and

$$
\sigma=\frac{\mathrm{Br}}{2 \sqrt{\ln (2)}} .
$$

After determination of $\varepsilon_{2}, \varepsilon_{1}$ can be expressed by KramersKronig transformation as

$$
\varepsilon_{1}=\frac{2}{\pi} P \int_{\mathrm{Eg}}^{\infty} \frac{\xi \varepsilon_{2}(\xi)}{\xi^{2}-E^{2}} \mathrm{~d}(\xi)
$$

where $P$ stands for the Cauchy principal part of the integral and $\xi$ is the energy. The parameters of $\varepsilon_{1}$ and $\varepsilon_{2}$ are simultaneously fitted to minimize MSE by using Levenberg-Marquardt regression algorithm. ${ }^{61}$ The real and imaginary parts of the complex refractive index $n$ and $k$ can be described as

$$
\begin{aligned}
& n=\left[0.5\left(\left(\varepsilon_{1}^{2}+\varepsilon_{2}^{2}\right)^{0.5}+\varepsilon_{1}\right)\right]^{0.5}, \\
& k=\left[0.5\left(\left(\varepsilon_{1}^{2}+\varepsilon_{2}^{2}\right)^{0.5}-\varepsilon_{1}\right)\right]^{0.5} .
\end{aligned}
$$

The absorption coefficient is proportional to the imaginary part of the refractive index as $\alpha=(4 \pi / \lambda) k$.

Swollen brushes were also modeled with the multilayer box model, since more complex models could not be applied successfully for these thin brush films. However, complex models are used for much thicker polymer films in the literature. ${ }^{62,63}$ For the monitoring of the temperature-dependent swelling/deswelling of the polymer brushes, the temperature of the cell was adjusted by a home-built heating stage equipped with test-Point software and the actual temperature at the brush surface was controlled. Heating and cooling cycles for each sample were performed between 15 and $40^{\circ} \mathrm{C}$ with a heating/cooling rate of $0.2{ }^{\circ} \mathrm{C} \mathrm{s}^{-1}$, and up to two cycles were measured.

The volume fraction of water inside the swollen polymer brush layer was modeled by an effective medium approach (EMA). In this approach, the effective dielectric function (refractive index $n$ ) of the heterogeneous layer is described on the basis of the known 
dispersion relations for $n$ of the two components with varying individual volume fractions. ${ }^{64}$ The EMA according to Bruggeman was used, where the following condition has to be fulfilled:

$$
0=f_{\mathrm{H}_{2} \mathrm{O}} \frac{n_{\mathrm{H}_{2} \mathrm{O}}{ }^{2}-n^{2}}{n_{\mathrm{H}_{2} \mathrm{O}}{ }^{2}+2 n^{2}}+f_{\text {polymer }} \frac{n_{\text {polymer }}{ }^{2}-n^{2}}{n_{\text {polymer }}^{2}+2 n^{2}}
$$

Here $f_{\mathrm{H}_{2} \mathrm{O}}$ and $f_{\text {polymer }}$ are the volume fractions of water and polymer in the mixed layer, respectively. $n_{\mathrm{H}_{2} \mathrm{O}}, n_{\text {polymer }}$, and $n$ represent the dispersion relationships of the refractive index for water, the dry polymer, and the mixed (swollen) layer. $n(\lambda)$ for water was taken from the software library. The Bruggeman approach is based on the assumption of a random mixture of polymer and water components with volume fractions of the same magnitude. No host medium can be assigned to one of the components.

\section{UV/VIS and fluorescence measurements}

All spectra were recorded with a Cary6000i spectrophotometer (Varian, spectral bandwidth: $1 \mathrm{~nm}$, averaging: $0.3 \mathrm{~s}$ ). Fluorescence spectra were measured with a Fluorolog 3 spectrofluorometer (Horiba Jobin Yvon, front face mode, spectral bandwidth: $3 \mathrm{~nm}$, integration time: $0.2 \mathrm{~s}$ ). For the measurements in water, the samples were fitted into a $10 \mathrm{~mm}$ standard cuvette by means of a special clamp.

\section{Results and discussions}

\section{Synthesis of bifunctional PNiPAAm}

The successful ATRP of NiPAAm with low polydispersity in $N, N^{\prime}$-dimethylformamide (DMF)-water mixtures was first reported by Masci et al. ${ }^{30} \mathrm{~A}$ modified version of their protocol was used to synthesize bifunctional PNiPAAm with distinct functional end groups suitable for the attachment to solid substrates while maintaining the other terminal functionalities active for subsequent postmodification reactions (e.g. CuAAC). Fig. 1 displays the reaction sequence for the preparation of bifunctionalized PNiPAAm. Herein, we used a $\mathrm{Cu}(\mathrm{I}) \mathrm{Cl}-\mathrm{Me}_{6} \mathrm{~T}$ REN system with tert-butyl $\alpha$-bromoisobutyrate $(t \mathrm{BBiB})$ as an initiator bearing a protected carboxylic group which can efficiently be used in "grafting-to" processes. Through the subsequent addition of (trimethylsilyl)propargyl acrylamide (TMSPAAm) a protected alkyne functionality was introduced to yield a bi-functionalized polymer termed pAlk-PNiPAAm. To ensure that the alkyne groups are located at or near the polymer chain ends the polymerization was conducted to near-completion before the addition of the second monomer, leading to only a small number of TMS-PAAm units at or near the polymer chain ends. After standard workup procedures the TMS-protecting group (TMS-PG) was removed with tetrabutyl-ammonium fluoride (TBAF) and yielded unprotected bi-functionalized polymer termed as Alk-PNiPAAm. The details of the polymer analysis of pAlk-PNiPAAm are summarized in Table 1. From ${ }^{1} \mathrm{H}-\mathrm{NMR}$ spectroscopy measurements a degree of polymerization (DP) of 420 (conv. 85\%) was found and thus a theoretical molar mass of $48300 \mathrm{~g} \mathrm{~mol}^{-1}$ could be obtained. The ${ }^{1} \mathrm{H}-\mathrm{NMR}$ spectrum (see ESI $\dagger$ ) also revealed the successful introduction of the TMS-protected alkyne functionality due to the proton signal of the three methyl groups from TMS at $\delta=0.13 \mathrm{ppm}$. The number of alkyne-containing units $\left(N_{\mathrm{Alk}} \sim 3\right)$ was calculated from the integral ratio of the single tertiary proton of the isopropyl group in NiPAAm and the nine methyl protons of the trimethylsilyl group in TMS-PAAm. Even if the number of alkyne-containing mers could be computed it is not clear whether they were consecutively added to the chain end or separated by one or more NiPAAm units. After treatment of pAlk-PNiPAAm with TBAF no TMS-signal could be detected. Instead, a new signal with 10-times lower intensity appeared at $\delta=3.05 \mathrm{ppm}$, which corresponds to the proton of the free acetylene group, indicating again the presence of the alkyne functionality in the polymer. GPC measurement showed a unimodal and symmetrical curve with narrow molecular weight distribution $\left(M_{\mathrm{w}} / M_{\mathrm{n}}=\right.$ 1.32), which is a characteristic of ATRP. ${ }^{65}$ The apparent $M_{\mathrm{n}}$ values measured by GPC were about twice as high as expected, as first observed by Müller's group. ${ }^{66}$

The thermogravimetric analysis (TGA, see ESI $\dagger$ ) of the asprepared polymers showed a weight loss of $4.3 \mathrm{wt} \%$ and $7.2 \mathrm{wt} \%$ up to $120{ }^{\circ} \mathrm{C}$ for Alk-PNiPAAm and pAlk-PNiPAAm, respectively, which we attribute to the adsorbed water from air humidity. By further heating until $300{ }^{\circ} \mathrm{C}$, no additional weight loss and thus no degradation process was found. From TGA measurements it is well known that residual alkyne groups decompose at around $275^{\circ} \mathrm{C} .{ }^{67}$ Due to the very small amount of alkyne groups in the as-prepared polymers, degradation may occur at these temperatures but cannot be detected. Decomposition of both polymers started to occur above $300{ }^{\circ} \mathrm{C}$, with a final loss of $98.5 \mathrm{wt} \%$ at $450{ }^{\circ} \mathrm{C}$. Therefore during the grafting-to process at $150{ }^{\circ} \mathrm{C}$ the protected and unprotected alkyne groups in the PNiPAAm polymer are assumed to remain stable over time without any degradation.

\section{Preparation of polymer brushes with RhB-N3 via CuAAC}

The resulting polymer brush systems were prepared through a "grafting-to" protocol developed in our group. In our studies we found that PNiPAAm end-functionalized with a tert-butyl protected carboxylic group can also be used like carboxy-terminated PNiPAAm for grafting to PGMA modified surfaces. The successful attachment is believed to occur due to a thermally induced cleavage of the tert-butoxy group and subsequent reaction of the resulting carboxylic acid with epoxy and/or hydroxy groups of PGMA during the melt reaction. Further mechanistic

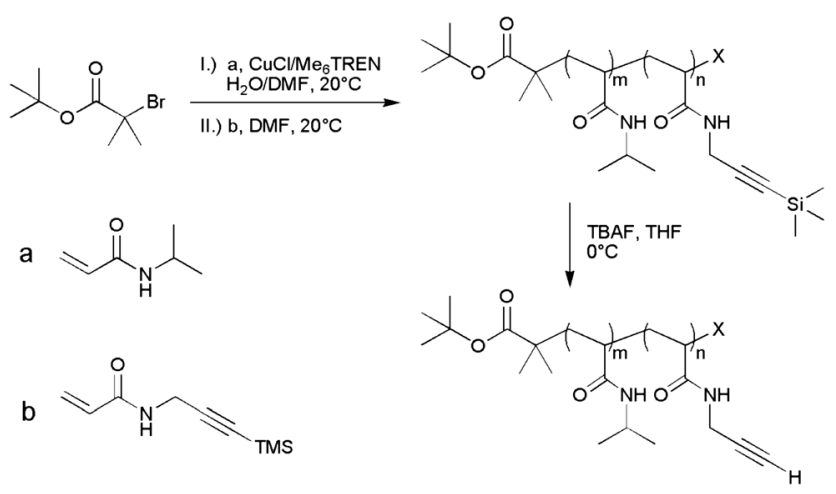

Fig. 1 Synthesis of bifunctional poly( $N$-isopropylacrylamide) (AlkPNiPAAm) via ATRP and subsequent removing of the TMS protecting group. 
Table 1 Summarized results of pAlk-PNiPAAm analysis

\begin{tabular}{llllll}
\hline $\mathrm{DP}^{a}$ & $M_{\mathrm{n}, \mathrm{th}}{ }^{b}\left(\mathrm{~g} \mathrm{~mol}^{-1}\right)$ & $M_{\mathrm{n}, \mathrm{GPC}}{ }^{c}\left(\mathrm{~g} \mathrm{~mol}^{-1}\right)$ & $M_{\mathrm{w}} / M_{\mathrm{n}}{ }^{c}$ & $N_{\mathrm{Alk}}{ }^{a}$ & $T_{\mathrm{g}}\left({ }^{\circ} \mathrm{C}\right)$ \\
\hline 420 & 48300 & 107000 & 1.32 & $\sim 3$ & 143
\end{tabular}

${ }^{a}$ From ${ }^{1} \mathrm{H}-\mathrm{NMR}$ spectroscopy. ${ }^{b} M_{\mathrm{n}, \mathrm{th}}=M_{\text {Initiator }}+\left(\mathrm{DP} \times M_{\text {NiPAAm }}\right)+$ $\left(N_{\text {Alk }} \times M_{\text {TMS-PAAm }}\right){ }^{c}$ From GPC in $2 \%(\mathrm{v} / \mathrm{v}) \mathrm{H}_{2} \mathrm{O}-\mathrm{DMAc}, 3 \mathrm{~g} \mathrm{~L}^{-1} \mathrm{LiCl}$.

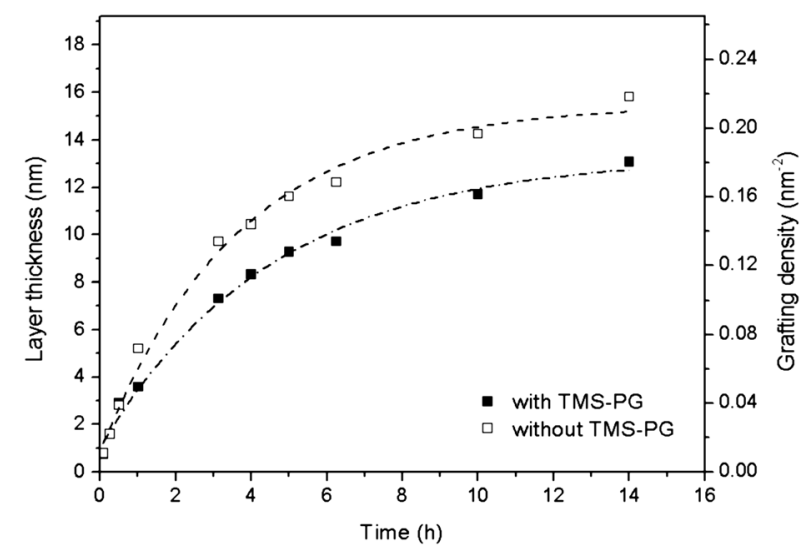

Fig. 2 Influence of the TMS protecting group (TMS-PG) on the layer thickness and grafting density, respectively, during the "grafting to" process of alkyne modified PNiPAAm as a function of time. Lines are added to guide the eye.

studies are planned and therefore are not part of this paper. The analysis of the typical brush parameters (grafting density $\sigma$ and distance between grafting sites $s$ ) was done based on the ellipsometric dry layer thickness $d$ using eqn (1)-(3), ${ }^{68}$ where $\rho$ is the density and $N_{\mathrm{A}}$ is Avogadro's number. The literature values for the density of bulk PNIPAAm range from $1.07 \mathrm{~g} \mathrm{~cm}^{-3}$ to $1.12 \mathrm{~g}$ $\mathrm{cm}^{-3} \cdot{ }^{69,70}$ Therefore a density of $1.1 \mathrm{~g} \mathrm{~cm}^{-3}$ was used for calculations.

$$
\begin{aligned}
& \Gamma_{\mathrm{P}}=d \rho \\
& \sigma=\frac{N_{\mathrm{A}} d \rho}{M_{\mathrm{n}}} \\
& s=\sigma^{-1 / 2}
\end{aligned}
$$

In Fig. 2 the time dependent evolution of film thickness, and grafting density in the dry state is shown for pAlk-PNiPAAm and Alk-PNiPAAm brushes, respectively. As expected, the density of the chains attached to the surface grows with grafting

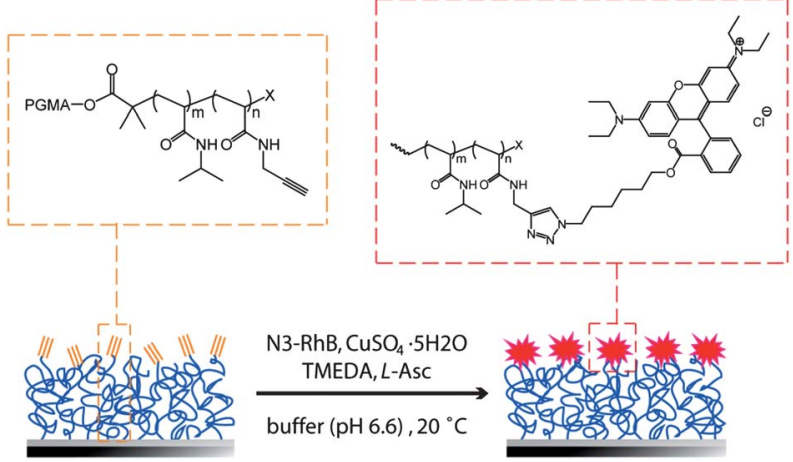

Fig. 3 Copper catalyzed alkyne-azide cycloaddition (CuAAC) reaction of (p)Alk-PNiPAAm brushes with azide modified rhodamine B (N3-RhB).

time and approaches values around $0.2 \mathrm{~nm}^{-2}$, which are typical for "grafting-to" brushes. ${ }^{1}$ Additionally, we observed consistent reduced grafting densities $\left(\sim-0.04 \mathrm{~nm}^{-2}\right)$ for pAlk-PNiPAAm

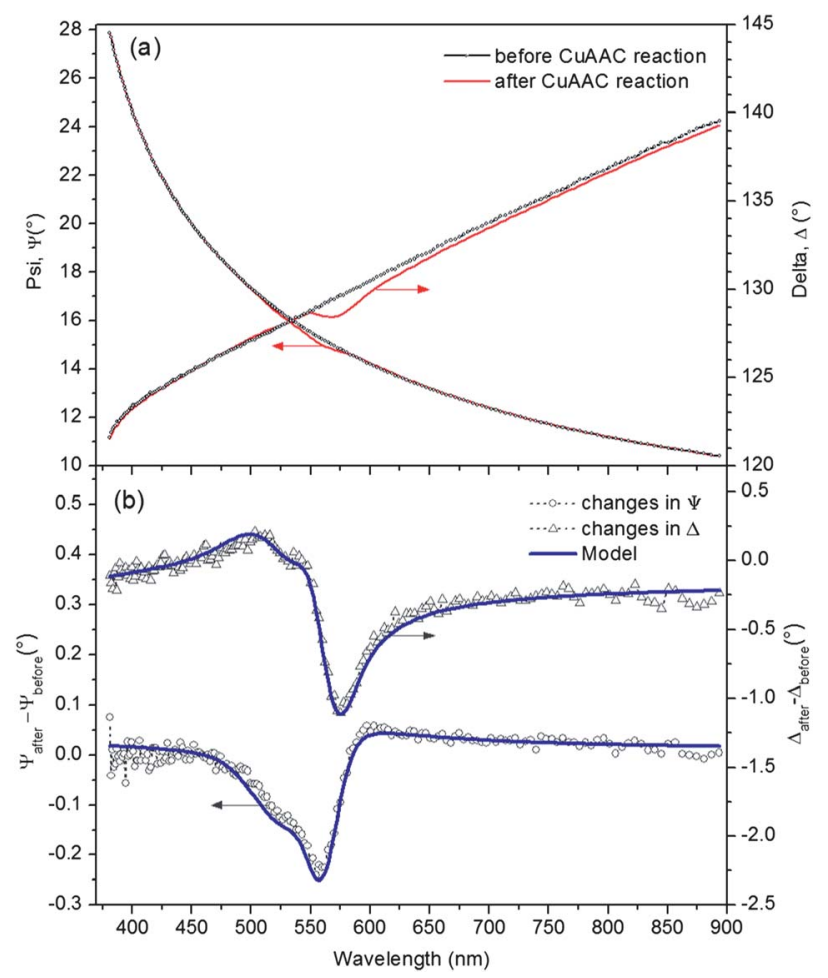

Fig. 4 Experimental data of $\Psi$ and $\Delta$ of an Alk-PNiPAAm brush $(\sigma=$ $0.20 \mathrm{~nm}^{-2}$ ) in the dry state before and after CuAAC reaction with N3$\mathrm{RhB}$ for $17 \mathrm{~h}$.

Table 2 Dry layer parameters (thickness $d$, surface concentration $\Gamma_{\mathrm{P}}$, grafting density, grafting distance $s$ and the corresponding brush criteria) of (p) Alk-PNiPAAm films for different grafting times ${ }^{a}$

\begin{tabular}{lccccc}
\hline Polymer & Time $(\mathrm{h})$ & $d(\mathrm{~nm})$ & $\Gamma_{\mathrm{P}}\left(\mathrm{mg} \mathrm{m}^{-2}\right)$ & $\sigma\left(\mathrm{nm}^{-2}\right)$ & $s(\mathrm{~nm})$ \\
\hline pAlk-PNiPAAm & 0.5 & 2.9 & 3.2 & 0.04 & 5.0 \\
& 5 & 9.3 & 10.2 & 0.13 & 0.22 \\
Alk-PNiPAAm & 14 & 13.1 & 14.4 & 0.18 & 0.12 \\
& 0.5 & 11.6 & 1.1 & 0.04 & 2.4 \\
& 5 & 15.8 & 17.4 & 0.16 & 5.1 \\
\end{tabular}

${ }^{a}$ For the calculations, a density of $\rho=1.1 \mathrm{~g} \mathrm{~cm}^{-3}$ and a Flory radius of $R_{\mathrm{F}}=11.25 \mathrm{~nm}$ was used. 
Table 3 Best-fit results from the ellipsometric analysis of Alk-PNiPAAm brushes before and after CuAAC with N3-RhB in the dry state and in situ

\begin{tabular}{llllll}
\hline Alk-PNiPAAm & Condition & $d(\mathrm{~nm})$ & $n_{\text {eff }}(750 \mathrm{~nm})$ & $k_{\text {eff }}(565 \mathrm{~nm})$ & $\mathrm{H}_{2} \mathrm{O}(\mathrm{vol} \%)$ \\
\hline Before CuAAC & Dry state & $14.42 \pm 0.01$ & 1.497 & - & - \\
& In situ $\left(15^{\circ} \mathrm{C}\right)$ & $78.55 \pm 0.24$ & 1.359 & - & $81.9 \pm 0.4$ \\
After CuAAC & In situ $\left(40{ }^{\circ} \mathrm{C}\right)$ & $23.04 \pm 0.11$ & 1.436 & - & 0.390 \\
& Dry state & $14.49 \pm 0.02$ & 1.515 & 0.041 & 0.065 \\
& In situ $\left(15^{\circ} \mathrm{C}\right)$ & $70.73 \pm 0.08$ & 1.366 & 0.495 \\
& In situ $\left(40^{\circ} \mathrm{C}\right)$ & $22.32 \pm 0.07$ & 1.441 & 0.024 & 0.527 \\
\hline
\end{tabular}

brushes above a reaction time of $1 \mathrm{~h}$. For shorter reaction times no significant changes in the layer thickness and grafting density could be detected. We attribute these differences to the presence of the bulky TMS-PG near or at the chain ends.

During the "grafting-to" process in melt $\left(T>T_{\mathrm{g}}\right)$, we believe that the polymer chain movements towards the PGMA surface are continuously hindered for steric reasons, leading to lower grafting densities. This effect is significant after $1 \mathrm{~h}$ because, from this point, the polymer molecules have to pass through a barrier of about $3 \mathrm{~nm}$ of already attached chains. This implies that, before one hour of reaction time, the spin-coated polymer chains with and without TMS-PG follow the same chain dynamics near the surface. To determine whether the grafted polymers are in the brush regime, the distance between grafting sites $s$ is compared to twice the Flory radius $R_{\mathrm{F}}=\alpha \times \mathrm{DP}^{3 / 5}$, assuming that water $(T<\mathrm{LCST})$ is a good solvent for PNIPAM. ${ }^{2}$ Here, $\alpha$ is the estimated monomer size $(0.3 \mathrm{~nm})$ and DP is the degree of polymerization. If $s \ll 2 R_{\mathrm{F}}$, then the chains form stretched brushes. ${ }^{71}$ The values of $R_{\mathrm{F}}$ and distances between grafting sites $s=\sigma^{-1 / 2}$ are summarized in Table 2 . With respect to the brush criterion, which was already applied for PNIPAAm brushes, ${ }^{1}$ the (p)AlkPNIPAAm films prepared with grafting times longer than 30 minutes are in the brush regime below the LCST at good solvent conditions. The presence and activity of the available alkyne functions at or near the end of the as-prepared polymer brushes are verified by the $\mathrm{CuAAC}$ reaction with an azide-modified rhodamine $\mathrm{B}$ dye $(\mathrm{N} 3-\mathrm{RhB})$, which is known for its high absorption coefficient. ${ }^{72}$ For this we used a modified CuAAC protocol, ${ }^{35}$ as depicted in Fig. 3, which is also applicable for bioconjugation. Herein, only a very low concentration of copper $(250 \mu \mathrm{M})$ was needed to ensure the successful covalent linkage of the rhodamine dye to the end of the polymer brush systems, as can be seen later from the ellipsometric and UV/VIS analysis. L-Ascorbic acid was used as a reducing agent to generate the active $\mathrm{Cu}(\mathrm{I})$ species which was coordinated by the ligand $N, N, N^{\prime}, N^{\prime}$-tetramethylethane-1,2-diamine (TMEDA) to ensure a stable catalytic system. This ligand has previously been reported to promote and enhance $\mathrm{Cu}$-catalyzed transformations ${ }^{73}$ and has been successfully used as a bidentate ligand in the coupling of imidazoles with arylboronic acids. ${ }^{74}$ After the reaction was complete, the samples were rinsed with water and stirred in a $50 \mathrm{mM}$ EDTA solution to remove trace amounts of copper. Unspecifically adsorbed N3-RhB molecules were removed by rinsing several times with EtOH. Due to the higher solubility of $\mathrm{N} 3-\mathrm{RhB}$ in EtOH, all non-specific adsorptions could be eliminated. Interestingly we found "click-activity" for both polymer brush systems (Alk-PNiPAAm and (p)Alk-PNiPAAm) and were surprised about this result, as it is well known that the CuAAC reaction works only with terminal alkynes. ${ }^{35}$ The explanation for this is given by the high temperature used for the preparation of the polymer brushes. At $150{ }^{\circ} \mathrm{C}$ degradation of about $\sim 60 \%$ of the TMS-groups in the polymer occurred, as it was proved by ${ }^{1} \mathrm{H}-\mathrm{NMR}$ spectroscopy (see ESI $\dagger$ ), while the amount of the cleaved TMS-groups was too low to be detected with TGA. This degradation process led to unprotected alkyne functionalities, which could be used for the CuAAC reaction with N3-RhB.

\section{Analysis of N3-RhB modified PNiPAAm brushes in dry state}

The physico-chemical properties of the as-prepared N3-RhB modified PNiPAAm brush films in both the dry state and in situ are investigated by means of SE and UV/VIS measurements. Prior to the discussion we want to emphasize the meaning of the optical constants $k_{\text {eff }}$ (effective extinction coefficient) and $n_{\text {eff }}$ (effective index of refraction), which are used in this paper. They are labeled as effective because they describe the optical properties of the complete thin film and not of a single component, for

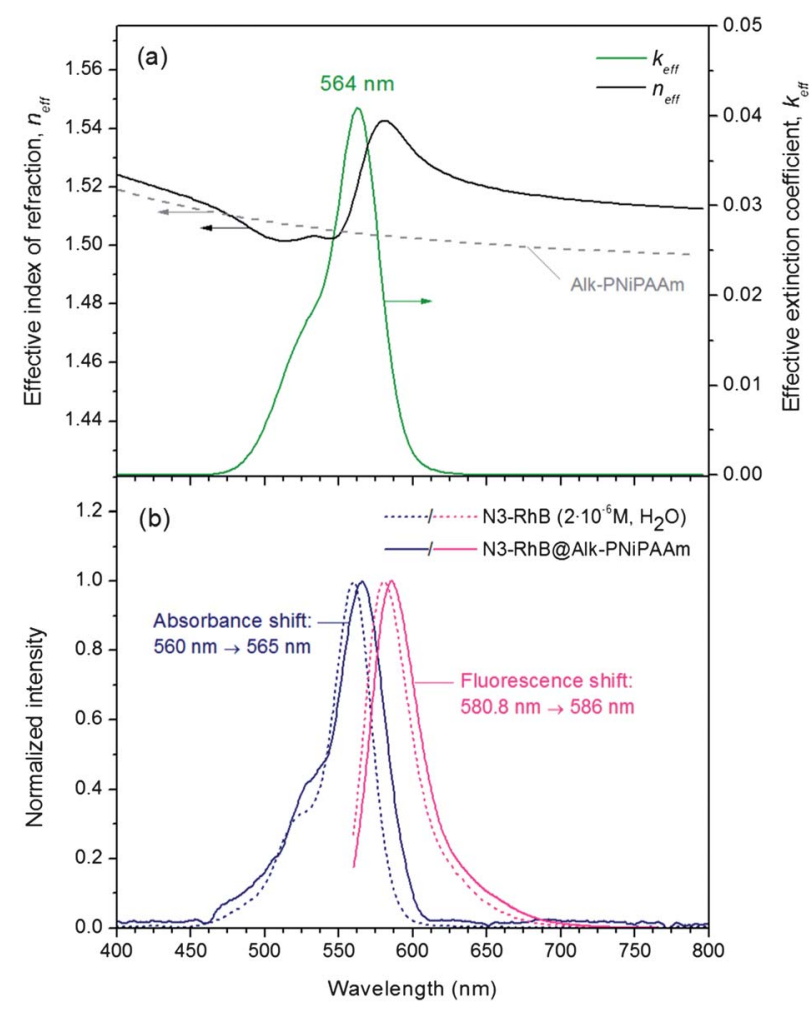

Fig. 5 (a) Effective index of refraction and extinction coefficient for a dry N3-RhB@Alk-PNiPAAm brush $\left(\sigma=0.20 \mathrm{~nm}^{-2}, \mathrm{SE}\right)$ as a function of wavelength and normalized absorbance and fluorescence spectra (b) of $\mathrm{N} 3-\mathrm{RhB}$ only and covalent attached to Alk-PNiPAAm brush (UV/VIS), respectively, are shown. 


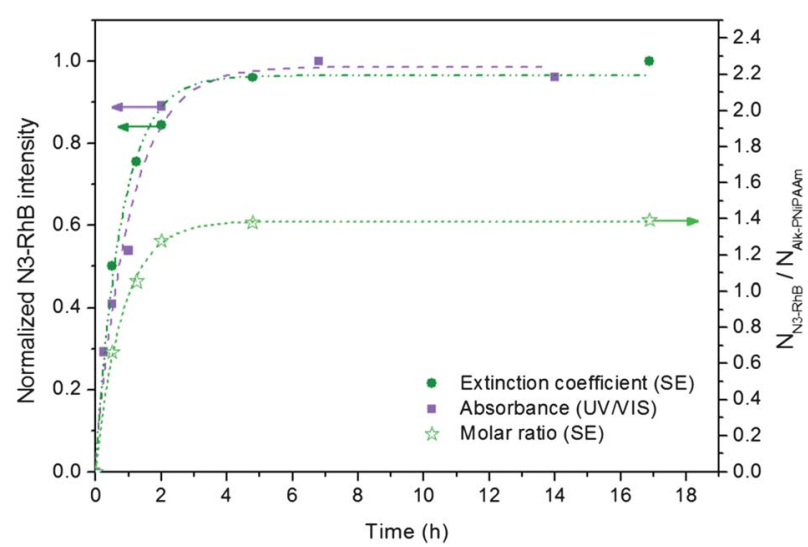

Fig. 6 Time dependent CuAAC reaction of N3-RhB with pAlk-PNiPAAm brushes $\left(\sigma=0.16 \mathrm{~nm}^{-2}\right)$ : normalized absorbance (FS-substrates, UV/VIS), normalized extinction coefficient (Si-substrates, SE), and corresponding dye to polymer molar ratio (SE), respectively, measured in the dry state. Lines are added to guide the eye.

e.g. the rhodamine dye. Generally the latter is characterized by its molar extinction coefficient $\varepsilon_{\mathrm{m}}$, which can be obtained from UV/ VIS measurements and is referred to in Beer's law as a constant. However the extinction coefficient $k$ and index of refraction $n$ obtained from SE measurements depend on the characteristics of the thin film and its conditions. So changes in the environment or constitution can affect the film properties and thus lead to changes in $n$ and $k$ even if the amount of the dye in the layer is constant. This remark is very important for the analysis of the swelling dynamics which will be discussed at the end of this section.

In Fig. 4 the experimental ellipsometric data (a), and changes in $\Delta$ and $\Psi$ (b) of an Alk-PNiPAAm brush $\left(\sigma=0.20 \mathrm{~nm}^{-2}\right)$ are compared before and after functionalisation with $\mathrm{N} 3-\mathrm{RhB}$ via CuAAC for $17 \mathrm{~h}$. Between 450 and $600 \mathrm{~nm}$ two absorption bands were detected with a maximum change of $(-1.102 \pm 0.019)^{\circ}$ at $588 \mathrm{~nm}$ for $\Delta$ and $(-0.241 \pm 0.003)^{\circ}$ at $557 \mathrm{~nm}$ for $\Psi$, which are characteristic for the $\pi-\pi^{*}$ electron transitions in N3-RhB dye. From these bare experimental data it can be seen that SE shows a

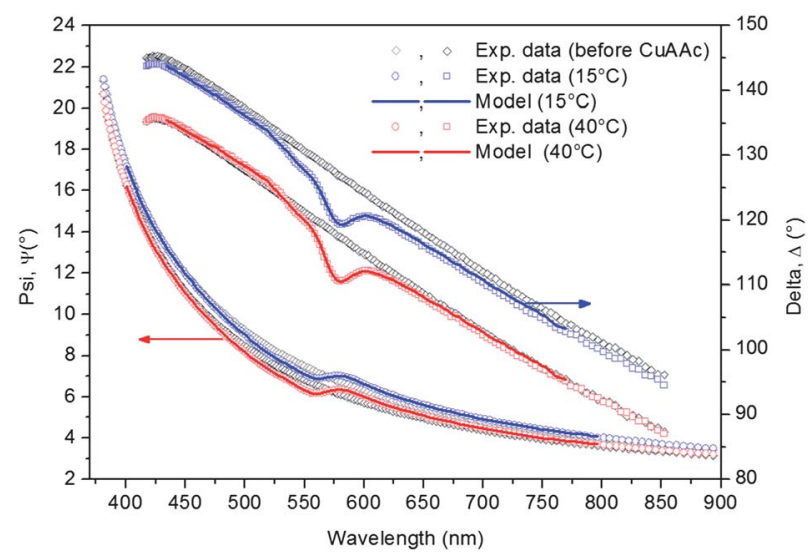

Fig. 7 Experimental data ( $\Psi$ and $\Delta$ ) from in situ ellipsometry of AlkPNiPAAm brushes $\left(\sigma=0.20 \mathrm{~nm}^{-2}\right)$ before (dark grey) and after CuAAC reaction with $\mathrm{N} 3-\mathrm{RhB}$ at $15{ }^{\circ} \mathrm{C}$ (blue) and $40{ }^{\circ} \mathrm{C}$ (red), respectively. The solid lines represent the best-fit results of the Gaussian oscillator model. high accuracy for the measured $\Delta$ and $\Psi$ and is sensitive enough to detect very small amounts of this dye, which absorbs in the visible spectral range. In the next step we applied a Gaussian oscillator model with two oscillators to fit the experimental data and to obtain the layer thickness and optical properties of the N3-RhB-modified PNiPAAm brush film in the dry state. A similar approach was used by Burns et al. to study the thermochromism in an ultrathin poly(diacetylene) film ${ }^{75}$ and thus shows the applicability of this ellipsometry model for the analysis of thin organic films with absorbing features in the UV/VIS region. The corresponding curves from the oscillator model are depicted in Fig. 4(b) and fit very well to the experimental data (MSE = 0.477). The best-fit results for a rhodamine B-modified AlkPNiPAAm brush $\left(\sigma=0.20 \mathrm{~nm}^{-2}\right)$ in the dry state are summarized in Table 3 and the resulting $n_{\text {eff }}$ and $k_{\text {eff }}$ as a function of wavelength are shown in Fig. 5(a). The wavelength-dependent $k_{\text {eff }}$ obtained from SE shows a maximum absorption peak at $564 \mathrm{~nm}\left(k_{\mathrm{eff}, \max }=0.041\right)$ with the characteristic band shape for the $\pi$-electron transitions in the N3-RhB dye.

The $n_{\text {eff }}$ of the N3-RhB modified polymer brush shows Kramers-Kronig consistency over the whole measured spectral range. Even the shoulder peak at $\sim 530 \mathrm{~nm}$, which is resolved in the experimental data, could be modeled, indicating the very good applicability of the oscillator model.

To validate these results UV/VIS measurements of N3-RhBmodified PNiPAAm brushes prepared on fused silica substrates were carried out. They were compared to the SE data, but also to the absorbance and fluorescence spectra of the modified

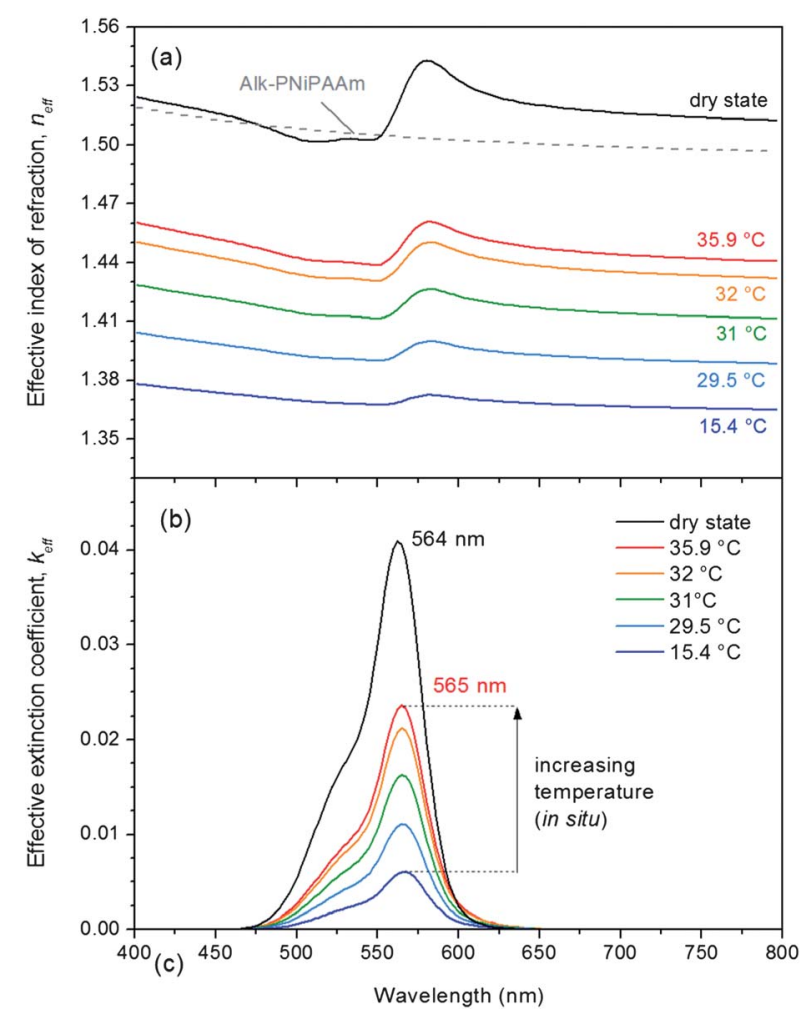

Fig. 8 Effective index of refraction (a) and effective extinction coefficient (b) for the N3-RhB@Alk-PNiPAAm brush $\left(\sigma=0.20 \mathrm{~nm}^{-2}, \mathrm{SE}\right)$ in the dry state and in situ for different temperatures, respectively, as a function of wavelength. 


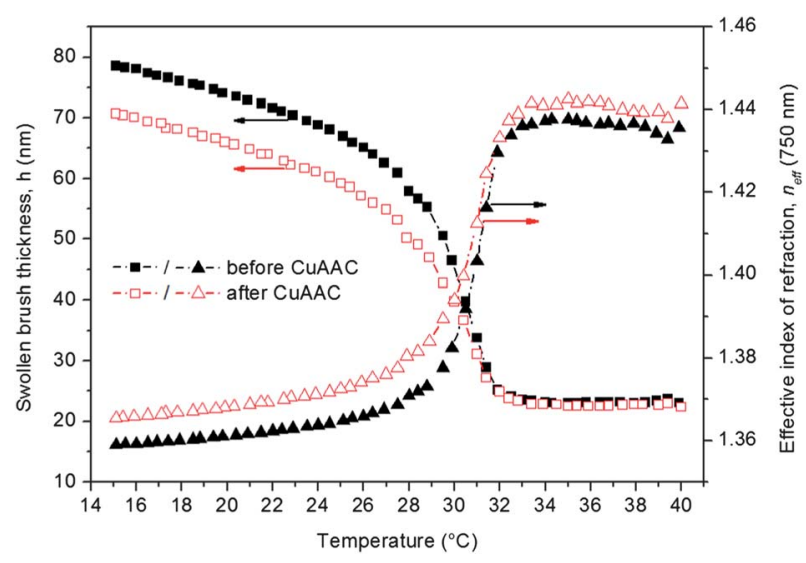

Fig. 9 Swollen brush thickness and effective refractive index at $\lambda=$ $750 \mathrm{~nm}$ of an Alk-PNiPAAm brush $\left(\sigma=0.20 \mathrm{~nm}^{-2}\right)$ before (black, closed symbols) and after (red, open symbols) CuAAC reaction with N3-RhB as a function of temperature. The evaluated data displayed are for the second cooling cycle.

rhodamine dye only in water [Fig. 5(b)]. A maximum absorption peak of $560 \mathrm{~nm}$ was found for the pure dye in solution, while attached to the PNiPAAm brushes it was shifted to a value of $565 \mathrm{~nm}$, similar to the results obtained from SE measurement. The fluorescence peak [Fig. 5(b)] of N3-RhB only in water showed a maximum at $580.8 \mathrm{~nm}$, while attached to the PNiPAAm brushes again a shift of $\sim 5 \mathrm{~nm}$ (to $586 \mathrm{~nm}$ ) was found. We believe that this red-shift of $\sim 5 \mathrm{~nm}$ is an effect of the changed polarity of the environment due to the attendant amide groups of the polymer brush. Similar effects could be observed for rhodamine B in $N, N$ dimethylacetamide and bonded to poly(methacrylic acid) leading to a red shift of 5 and $9 \mathrm{~nm}$, respectively. ${ }^{76}$ Specifically we attribute these interactions to $\mathrm{N}-\mathrm{H}-\pi$ hydrogen bonding between the amide groups of the brush and the aromatic residues of the rhodamine dye. These known attractive amide $-\pi$ interactions ${ }^{77}$ are weakly polar and have been identified to play a role in protein structures ${ }^{78}$ and enzyme-ligand binding. ${ }^{79}$

They have been established through data-mining studies of protein crystal structures, ${ }^{78}$ but also ${ }^{1} \mathrm{H}-\mathrm{NMR}$ spectroscopy has been used to identify Ar-HN interactions. ${ }^{80,81}$ As can be seen later in the text, we also observed changes in the swelling properties of the dye-modified polymer brushes and attribute them to these interactions too.

Fig. 6 shows the time dependence of the CuAAC reaction monitored via SE and UV/VIS measurements. For comparison, the intensities obtained from both methods were normalized by dividing by the maximum value. From here it can be seen that the reaction proceeded very quickly and reached a plateau after $5 \mathrm{~h}$. With both techniques, almost identical kinetic behaviour of the CuAAC reaction could be observed, which demonstrates the applicability of SE to monitor such reactions. To have a more detailed view on the covalent linkage of $\mathrm{N} 3-\mathrm{RhB}$ to the brush ends, the molar ratio of dye to polymer was calculated using a calibration curve (see ESI $\dagger$ ). For this purpose, polymer solutions with varying dye concentrations were prepared, spincoated on a PGMA-modified silicon substrate for two series and afterwards analysed by SE (see ESI $\dagger$ ).

From NMR analysis, $\sim 3$ alkyne groups per chain were found which means a maximum ratio of 3 can be reached for the

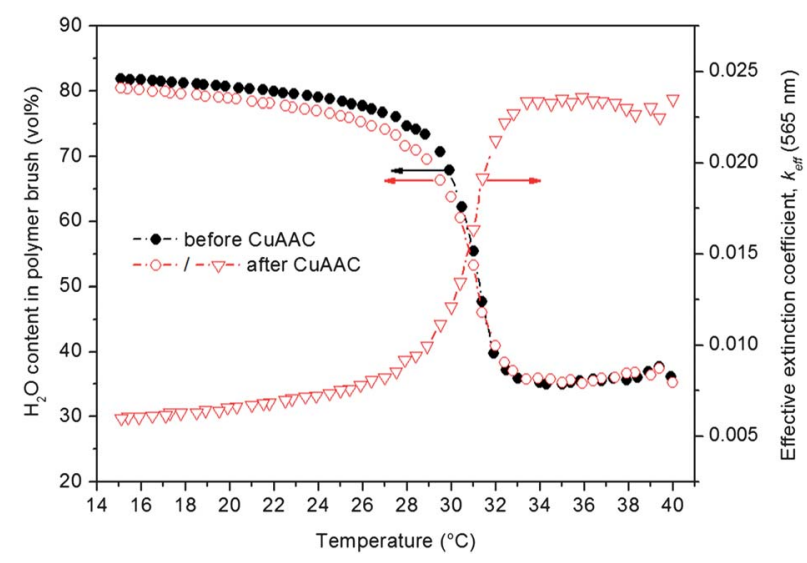

Fig. 10 Percentage of water content in the brush film and effective extinction coefficient at $\lambda=565 \mathrm{~nm}$ of an Alk-PNiPAAm brush $(\sigma=$ $0.20 \mathrm{~nm}^{-2}$ ) before (black, closed symbols) and after (red, open symbols) CuAAC reaction with N3-RhB as a function of temperature. The evaluated data displayed are for the second cooling cycle.

CuAAC reaction of N3-RhB with alkyne modified PNiPAAm brushes. Concerning that $\sim 60 \%$ of the TMS-protected alkyne groups were cleaved during the "grafting to" step, $\sim 1.8$ free alkyne functionalities should be present in the pAlk-PNiPAAm brushes. From Fig. 6 it can be seen that a maximum ratio of $\sim 1.4$ is achieved for pAlk-PNiPAAm brushes with a grafting density of $0.16 \mathrm{~nm}^{-2}$, which corresponds to a click efficiency of $78 \%$. It also means that every polymer brush should be functionalized at least with one rhodamine molecule. A molar dye to brush ratio of $\sim 1$ is already reached after $\sim 0.5 \mathrm{~h}$, but does not imply that exactly one dye is attached to one brush. Therefore a minimum reaction time of $5 \mathrm{~h}$ should be used to reach a saturated brush surface under these conditions.

\section{Swelling dynamics studied by in situ SE}

After the successful functionalization of the Alk-PNiPAAm brushes with $\mathrm{N} 3-\mathrm{RhB}$, we analyzed the temperature-dependent swelling characteristics of the system by SE. For this, we performed two heating-cooling cycles from $15^{\circ} \mathrm{C}$ to $40^{\circ} \mathrm{C}$ with steps of $0.5^{\circ} \mathrm{C}$ and applied the oscillator model in combination with an effective medium approach to determine the swollen brush thickness, the optical constants and the water content inside the brush. In Fig. 7, the experimental $\Psi$ and $\Delta$ values and the corresponding curves from the applied model for a dye-modified polymer brush $\left(\sigma=0.20 \mathrm{~nm}^{-2}\right)$ are depicted for $15^{\circ} \mathrm{C}$ and $40^{\circ} \mathrm{C}$, respectively. According to the experimental data from the dry state sample again one can see clearly the absorption band of the N3-RhB dye whereas in situ (at both temperatures) the magnitude of Delta and Psi in the absorption region increased by a factor of $\sim 7$ for $\Delta(-7.187 \pm 0.102)^{\circ}$ and of $\sim 2$ for $\Psi(-0.512 \pm$ $0.005)^{\circ}$. But this amplification in the in situ state is only caused by the changed ambient (from air to water), which influences the properties of the reflected, polarized light. To check this, assumption values of $\Delta$ and $\Psi$ of the dry N3-RhB@Alk-PNiPAAm brushes were simulated for different ambients $\left(n_{\text {ambient }}=\right.$ $1.00-1.33$, see ESI $\dagger$ ) and verified this hypothesis. However, this enhanced contrast may be used to study interaction processes at 


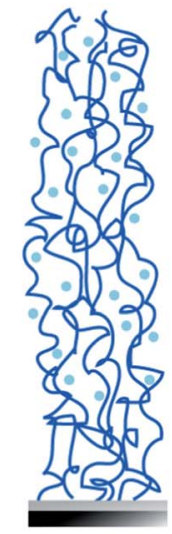

Alk-PNiPAAm brush

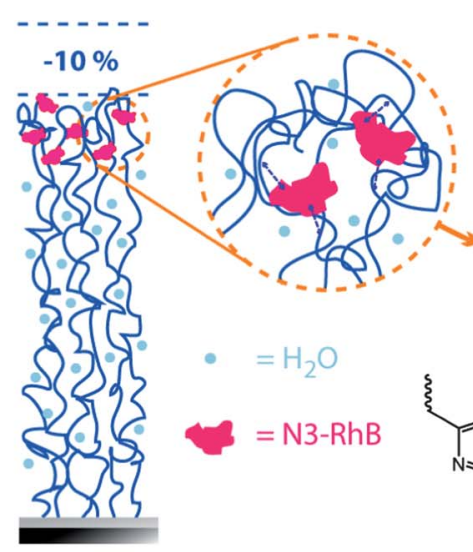

Alk-PNiPAAm

brush + N3-RhB

Fig. 11 Decrease of the swollen polymer brush thickness due to proposed $\mathrm{N}-\mathrm{H}-\pi$ hydrogen bonding of the amide groups of the polymer brush with the aromatic residues of attached N3-RhB.

the water-brush-dye interface with molecules or nanoparticles under aqueous conditions and thus exhibits high potential as a sensor system. A similar effect was used by Garcia and Nejadnik to increase the sensitivity of ellipsometric measurements in adsorption studies. ${ }^{82}$ Herein, they used a Coomassie brilliant blue $\mathrm{G}$ dye, which reacted with adsorbed proteins on a $\mathrm{SiO}_{2}$ substrate and enhanced the sensitivity by a factor of 2.5 in the subsequent analysis by SE. The wavelength-dependent $n_{\text {eff }}$ and $k_{\text {eff }}$ at different temperatures in the in situ state are shown in Fig. 8(a) and (b), respectively. From Fig. 8(b) it can be seen that the characteristic absorption band of the N3-RhB dye could be successfully extracted from the used SE model. For all temperatures a peak position of $565 \mathrm{~nm}$ was found, which is consistent with results obtained from UV/VIS measurements [Fig. 5(b)]. Additionally, from Fig. 8(b), it can be seen that the magnitude of $k_{\text {eff }}$ changes with temperature but never reaches the dry state value of 0.041 . In the swollen state at temperatures below the LCST, an effective extinction coefficient of $0.006\left(T=15.4{ }^{\circ} \mathrm{C}\right)$ is found whereas with elevated temperatures $k_{\text {eff }}$ increases up to $0.024\left(T=35.9^{\circ} \mathrm{C}\right)$. To understand this effect, as noted before, it is important to distinguish between the optical properties of the complete thin film and the dye itself.

The concentration of N3-RhB was constant at any time during these temperature dependent measurements, but the swelling dynamics of the polymer brush changed, leading to different optical properties of this thin film system as measured by SE. In Fig. 9 the swollen brush thickness and the effective index of refraction of an Alk-PNiPAAm brush with N3-RhB are shown as a function of temperature before and after functionalization, respectively. Under both conditions a LCST of $31{ }^{\circ} \mathrm{C}$ was found (see ESI $\dagger$ ). For the unmodified polymer brush, a swollen $\left(T=15^{\circ} \mathrm{C}\right)$ film thickness of $78.6 \mathrm{~nm}$ with $n_{\mathrm{eff}}=1.359$ was measured, while in the collapsed state $\left(T=40{ }^{\circ} \mathrm{C}\right)$ a film thickness of $23 \mathrm{~nm}$ with $n_{\mathrm{eff}}=1.436$ was obtained. After the CuAAC reaction with $\mathrm{N} 3-\mathrm{RhB}$ the swollen brush thickness decreased by $10 \%$ to $70.7 \mathrm{~nm}$ with $n_{\text {eff }}=1.366$. No significant changes in the collapsed film thickness $(h=23 \mathrm{~nm})$ and effective refractive index $\left(n_{\text {eff }}=1.441\right)$ of the N3-RhB-modified polymer brush were found after passing the LCST. From the Bruggeman-EMA, the water content in the brush film was calculated and is depicted in Fig. 10 in addition to the effective extinction coefficient as a function of temperature.

This figure explains the varying $k_{\text {eff }}$ values for the different temperatures. For the extraction of information from the dynamic polymer brush system a SE box-model is used, which consists of three components: polymer, dye and water. Given that water is the only varying component during swelling and collapsing of the brush system, the overall optical properties of the thin film explicitly depend on the volume fraction of $\mathrm{H}_{2} \mathrm{O}$. As a consequence of a high water content of $82 \mathrm{vol} \%$ in the polymer brush in the swollen state $\left(T=15^{\circ} \mathrm{C}\right)$, the optical constants $n_{\text {eff }}$ and $k_{\text {eff }}$ of the film must change to lower values. And vice versa with increasing temperature ( $T>$ LCST) those values should increase, as can be seen from Fig. 9 and 10, respectively. The calculated water content decreased by $1.5 \mathrm{vol} \%$ after the $\mathrm{CuAAC}$ reaction below the LCST, whereas in the collapsed state, in addition to the measured $h$ and $n_{\text {eff }}$ (Fig. 9), no significant changes occurred. The reduction of the water content is connected to the reduced swollen brush thickness $(-10 \%)$, which is thought to be the consequence of possible $\mathrm{N}-\mathrm{H}-\pi$ hydrogen bonding of the polymer brush with the N3-RhB dye, as mentioned before in the text and depicted in Fig. 11. The proposed interactions are possible due to the quadrupole-dipole nature of the aromatic $\pi$-system ${ }^{77}$ of the dye. The strength of this interaction in a vacuum $\left(1-4 \mathrm{kcal} \mathrm{mol}^{-1}\right)$ is comparable with that of a conventional hydrogen bond $(2-7 \mathrm{kcal}$ $\left.\mathrm{mol}^{-1}\right) .{ }^{77}$ Therefore, we assumed this $\mathrm{N}-\mathrm{H}-\pi$ hydrogen bonding will break during the heating-cooling cycles and be replaced by hydrogen bonding with water molecules. But for both cycles the same heating and cooling curves were measured and no recovery of the original thickness was observed (see ESI $\dagger$ ). So we also assume contributions from sterical effects. Specifically, the dye molecule is thought to be in a fixed state inside the brush, which leads to a conformational barrier of the polymer brush and thus to a hindered mobility in the region with the N3-RhB dye. We assume this region to be near the end of the stretched polymer chains, while the behavior of the residual part of the brush is similar to the unmodified state. This is supported by the same trend of the heating-cooling curves of the modified and unmodified Alk-PNiPAAm system, respectively. During heating (up to $31^{\circ} \mathrm{C}$ ) the difference in the swollen film thickness is constant and 
disappears after passing the LCST (Fig. 9) and appears again after passing $31{ }^{\circ} \mathrm{C}$ during the cooling step. In the collapsed brush regime (more hydrophobic), the N3-RhB molecules are embedded well in or between the chains and no significant changes could be observed.

\section{Conclusions}

In this work, the preparation and ellipsometric analysis of the swelling dynamics of a new temperature responsive polymer brush system with "click"-functionality is presented for the first time. For this ATRP was used to synthesize bi-functionalized poly( $N$-isopropylacrylamide) with one chain end used for the "grafting to" approach while the other free end remains active for postmodification reactions via "click" chemistry. Afterwards, the synthesized PNiPAAm was characterized using ${ }^{1} \mathrm{H}-\mathrm{NMR}$ spectroscopy, GPC, TGA and DSC. The presence of alkyne groups in the polymer was confirmed by ${ }^{1} \mathrm{H}-\mathrm{NMR}$ spectroscopy and calculated to be $\sim 3$ per polymer chain. Using the grafting-to approach, well-defined brush films with a smooth surface were obtained, while maintaining the alkyne functionality active for postmodification reactions via CuAAC. Furthermore, it was shown that the TMS-residue from the protected alkyne group affected the grafting-to behavior of the PNiPAAM chains for sterical reasons and led to lower grafting densities in comparison with unprotected ones. The availability and activity of the alkyne groups in the PNiPAAm brush was proven by the CuAAC reaction with an azide-modified rhodamine $\mathrm{B}$ dye and subsequent analysis by SE and UV/VIS spectroscopy. Measurements by SE were sensitive enough to detect very small amounts of rhodamine B. The optical properties and thicknesses of the dyemodified polymer brush films could be extracted using a Gaussian oscillator model and agreed well with the data from UV/VIS measurements. A red shift of $\sim 5 \mathrm{~nm}$ was found for the absorption peak of the attached rhodamine dye in dry state and in situ. We attribute this shift to weakly polar $\mathrm{N}-\mathrm{H}-\pi$ hydrogen bonding between the amide groups of the brush and the aromatic residues of the dye. Below the LCST, a reduction of the swollen brush thickness and water content inside the brush was observed whereas in the collapsed state no significant changes were seen. This observation was reproducible and led to the hypothesis of a second effect originated by a conformational barrier near the end of the polymer chains due to fixed dye molecules in this region, leading to hindered mobility and different swelling dynamics.

In this work we used an azide-modified rhodamine dye to prove the functionality of this new polymer brush system. But the dye can also be replaced by other azide-functionalized components, like macromolecules, proteins or nanoparticles via a $\mathrm{CuAAC}$ reaction, which implies the modular character of the new polymer brush system presented in this work. Thus, it offers high potential for diverse future applications, such as a sensor system to study interfacial processes or as a smart surface to control bioadhesion.

\section{Acknowledgements}

The authors gratefully acknowledge financial support from the German Science Foundation in the frame of the priority program SPP 1369 (DFG Project no. Sta 324/37) and the German
Ministry of Education and Research (BMBF Grant no. 16SV5340). The authors thank P. Treppe for GPC, B. Pilch for UV/VIS/Fluorescence, L. Häußler and K. Arnhold for TGA/ DSC measurements, as well as J. Gerasimov for helping with the manuscript.

\section{References}

1 E. Bittrich, S. Burkert, M. Müller, K.-J. Eichhorn, M. Stamm and P. Uhlmann, Langmuir, 2012, 28, 3439-3448.

2 C. Xue, N. Yonet-Tanyeri, N. Brouette, M. Sferrazza, P. V. Braun and D. E. Leckband, Langmuir, 2011, 27, 8810-8818.

3 I. Luzinov, S. Minko and V. V. Tsukruk, Prog. Polym. Sci., 2004, 29, 635-698.

4 M. Heskins and J. E. Guillet, J. Macromol. Sci., Chem., 1968, 2, 14411455.

5 L. D. Taylor and L. D. Cerankowski, J. Polym. Sci., Polym. Chem. Ed., 1975, 13, 2551-2570.

6 V. O. Aseyev, H. Tenhu and F. Winnik, Adv. Polym. Sci., 2006, 196, $1-85$.

7 Y. Maeda, T. Nakamura and I. Ikeda, Macromolecules, 2001, 34(5), 1391.

8 F. Meersman, J. Wang, Y. Q. Wu and K. Heremans, Macromolecules, 2005, 38(21), 8923.

9 H. Cheng, L. Shen and C. Wu, Macromolecules, 2006, 39(6), 2325.

10 Y. Katsumoto, T. Tanaka, H. Sato and Y. Ozaki, J. Phys. Chem. A, 2002, 106(14), 3429-3435.

11 Y. Okada and F. Tanaka, Macromolecules, 2005, 38(10), 4465.

12 M. V. Deshmukh, A. A. Vaidya, M. G. Kulkarni, P. R. Rajamohanan and S. Ganapathy, Polymer, 2000, 41, 7951-7960.

13 M. Nitschke, S. Gramm, T. Götze, M. Valtink, J. Drichel, B. Voit, K. Engelmann and K. Werner, J. Biomed. Mater. Res., Part A, 2007, 80, 1003-1010.

14 D. Kuckling, H.-J. P. Adler, L. Ling, W. D. Habicher and K.-F. Arndt, Macromol. Chem. Phys., 2000, 201, 273-280.

15 H. Kawaguchi, K. Fujimoto and Y. Mizuhara, Colloid Polym. Sci., 1992, 270, 53-57.

16 Y. Akiyama, A. Kikuchi, M. Yamato and T. Okano, Langmuir, 2004, 20, 5506-5511.

17 J. Yang, M. Yamato and T. Okano, MRS Bull., 2005, 30, 189-193.

18 M. Motornov, R. Sheparovych, E. Katz and S. Minko, ACS Nano, $2008,2,41-52$.

19 A. M. Granville and W. J. Brittain, Macromol. Rapid Commun., 2004, 25, 1298-1302.

20 Y. S. Park, Y. Ito and Y. Imanishi, Chem. Mater., 1997, 9, 2755-2758.

21 P. Uhlmann, N. Houbenov, N. Brenner, K. Grundke, S. Burkert and M. Stamm, Langmuir, 2007, 23, 57-64.

22 B. Zdyrko, V. Klep, X. Li, Q. Kang, S. Minko, X. Wen and I. Luzinov, Mater. Sci. Eng., C, 2009, 29, 680-684.

23 A. N. Constable and W. J. Brittain, Colloids Surf., A, 2007, 308, 123-128.

24 S. Gupta, M. Agrawal, P. Uhlmann, U. Oertel and M. Stamm, Macromolecules, 2008, 41, 8152-8158.

25 S. Burkert, E. Bittrich, M. Kuntzsch, M. Müller, K.-J. Eichhorn, P. Uhlmann and M. Stamm, Langmuir, 2010, 26, 1786-1795.

26 C. Xue, N. Yonet-Tanyeri, N. Brouette, M. Sferrazza, P. V. Braun and D. E. Leckband, Langmuir, 2011, 27, 8810-8818.

27 K. L. Beers, S. G. Gaynor, K. Matyjaszewski, S. S. Sheiko and M. Moeller, Macromolecules, 1998, 31, 9413-9415.

28 K. Matyjaszewski and J. Xia, Chem. Rev., 2001, 101, 2921-2990.

29 W. A. Braunecker and K. Matyjaszewski, Prog. Polym. Sci., 2007, 32, 93-146.

30 G. Masci, L. Giacomelli and V. Crescenzi, Macromol. Rapid Commun., 2004, 25, 559-564.

31 J. Ye and R. Narain, J. Phys. Chem. B, 2009, 113, 676-681.

32 A. Narumi, K. Fuchise, R. Kakuchi, A. Toda, T. Satoh, S. Kawaguchi, K. Sugiyama, A. Hirao and T. Kakuchi, Macromol. Rapid Commun., 2008, 29, 1126-1133.

33 P.-E. Millard, N. Mougin, A. Böker, A. H. E. Müller, Controlled Living Radical Polymerization: Progress in ATRP, ed. $\mathrm{K}$. Matyjaszewski, ACS Symp. Ser. 1023, American Chemical Society, Washington, D.C, 2009, p. 127.

34 P. L. Golas and K. Matyjaszewski, QSAR Comb. Sci., 2007, 26(1112), 1116-1134. 
35 H. C. Kolb, M. G. Finn and K. B. Sharpless, Angew. Chem., Int. Ed., 2001, 40, 2004-2021; V. Hong, S. I. Presolski, C. Ma and M. G. Finn, Angew. Chem., Int. Ed., 2009, 48, 9879-9883.

36 C. J. Hawker and K. L. Wooley, Science, 2005, 309, 1200-1205.

37 P. Wu, A. K. Feldman, A. K. Nugent, C. J. Hawker, A. Scheel, B. Voit, J. Pyun, J. M. J. Frechet, K. B. Sharpless and V. V. Fokin, Angew. Chem., Int. Ed., 2004, 43, 3928-3932.

38 R. Vukićević, U. Schwadtke, S. Schmücker, P. Schäfer, D. Kuckling and S. Beuermann, Polym. Chem., 2012, 3, 409-414.

39 D. Fournier, R. Hoogenboom and U. S. Schubert, Chem. Soc. Rev., 2007, 36, 1369.

40 M.-A. Berthet, Z. Zarafshani, S. Pfeifer and J.-F. Lutz, Macromolecules, 2010, 43, 44-50.

41 A. S. Lang, A. Neubig, M. Sommer and M. Thelakkat, Macromolecules, 2010, 43, 7001-7010.

42 H. Nandivada, H. Y. Chen, L. Bondarenko and J. Lahann, Angew. Chem., Int. Ed., 2006, 45, 3360.

43 S. Fleischmann, K. Hinrichs, U. Oertel, S. Reichelt, K. J. Eichhorn and B. Voit, Macromol. Rapid Commun., 2008, 29, 1177.

44 J. M. Spruell, M. Wolffs, F. A. Leibfarth, B. C. Stahl, J. Heo, L. A. Connal, J. Hu and C. J. Hawker, J. Am. Chem. Soc., 2011, 133, 16698-16706.

45 J. F. Lutz and H. G. Börner, Prog. Polym. Sci., 2008, 33, 1.

46 A. J. Dirks, J. J. L. M. Cornelissen, F. L. van Delft, J. C. M. van Hest, R. J. M. Nolte, A. E. Rowan and F. P. J. T. Rutjes, QSAR Comb. Sci., 2007, 26, 1200.

47 J. A. Opsteen and J. C. M. van Hest, Macromol. Eng., 2007, 4, 2645.

48 H. Yim, M. S. Kent, S. Mendez, G. P. Lopez, S. Satija and Y. Seo, Macromolecules, 2006, 39, 3420-3426.

49 M. Erber, J. Stadermann and K.-J. Eichhorn, Macromol. Symp., 2011, 305, 101-107.

50 R. Toomey and M. Tirrell, Annu. Rev. Phys. Chem., 2008, 59, 493517.

51 S. Balamurugan, S. Mendez, S. S. Balamurugan, M. J. O'Brie and G. P. Lopez, Langmuir, 2003, 19, 2545-2549.

52 K. N. Plunkett, X. Zhu, J. S. Moore and D. E. Leckband, Langmuir, 2006, 22, 4259-4266.

53 X. Zhu, C. Yan, F. M. Winnik and D. Leckband, Langmuir, 2007, 23, $162-169$.

54 Y. G. Takei, T. Aoki, K. Sanui, N. Ogata, Y. Sakurai and T. Okano, Macromolecules, 1994, 27, 6163-6166.

55 T. Korten, W. Birnbaum, D. Kuckling and S. Diez, Nano Lett., 2012, 12, 348-358.

56 M. Malkoch, R. J. Thibault, E. Drockenmuller, M. Messerschmidt, B. Voit, T. P. Russell and C. J. Hawker, J. Am. Chem. Soc., 2005, 127, 14942-14949.
57 X. Wei, W. Chen, X. Chen and T. P. Russell, Macromolecules, 2010, 43, 6234-6236.

58 B. Zdyrko, K. S. Iyer and I. Luzinov, Polymer, 2006, 47, 272-279.

59 C. Werner, K. J. Eichhorn, K. Grundke, F. Simon, W. Grahlert and H. J. Jacobasch, Colloids Surf., A, 1999, 156, 3-17.

60 D. W. Van Krevelen, Properties of Polymers, Elsevier, Amsterdam, 1997.

61 J. A. Woollam, B. Johs, C. M. Herzinger, J. Hilfiker, R. Synowicki and C. L. Bungay, Crit. Rev. Opt. Sci. Technol., 2002, 72, 3.

62 J. Habicht, M. Schmidt, J. Rühe and D. Johannsmann, Langmuir, 1999, 15, 2460-2465.

63 M. J. N. Junk, I. Anac, B. Menges and U. Jonas, Langmuir, 2010, 26, 12253-12259.

64 D. E. Aspnes, Thin Solid Films, 1982, 89, 249-262.

65 J. S. Wang and K. Matyjaszewski, J. Am. Chem. Soc., 1995, 117, $5614-5615$.

66 C. Schilli, M. G. Lanzendörfer and A. H. E. Müller, Macromolecules, 2002, 35, 6819-6827.

67 T. Muller and S. Bräse, Angew. Chem., Int. Ed., 2011, 50, 11844 11845.

68 W. J. Brittain and S. Minko, J. Polym. Sci., Part A: Polym. Chem., 2007, 45, 3505-3512.

69 N. L. Jeon, I. S Choi, G. M. Whitesides, N. Y. Kim, P. E. Laibinis, Y. Harada, K. Finnie, G. S. Girolami and R. G. Nuzzo, Appl. Phys. Lett., 1999, 75, 4201.

70 H. G. Schild, Prog. Polym. Sci., 1992, 17, 163.

71 J. Israelachvili, Intermolecular and Surface Forces, Academic Press, New York, 2nd edn, 1992.

72 H. Nishikiori and T. Fujii, J. Phys. Chem. B, 1997, 101, 3680-3687.

73 J. P. Collman, M. Zhong, C. Zhang and S. Costanzo, J. Org. Chem., 2001, 66, 7892-7897.

74 S. Ciampi, T. Bocking, K. A. Kilian, M. James, J. B. Harper and J. J. Gooding, Langmuir, 2007, 23, 9320-9329.

75 R. W. Carpick, T. M. Mayer, D. Y. Sasaki and A. R. Burns, Langmuir, 2007, 16, 4639-4647.

76 K. Kemnitz, N. Tamai, I. Yamazaki, N. Nakashima and K. Yoshihara, J. Phys. Chem., 1986, 90, 5094-5101.

77 G. Tóth, C. R. Watts, R. F. Murphy and S. Lovas, Proteins: Struct., Funct., Genet., 2001, 43, 373-381.

78 P. Ottiger, C. Pfaffen, R. Leist and S. Leutwyler, J. Phys. Chem. B, 2009, 113, 2937-2943.

79 M. F. Perutz, Philos. Trans. R. Soc. London, Ser. A, 1993, 345, 105.

80 J. Kemmink and T. E. Creighton, J. Mol. Biol., 1995, 243, 251-260.

81 G. A. Worth and R. C. Wade, J. Phys. Chem., 1995, 99, 17473-17482.

82 M. R. Nejadnik and C. D. Garcia, Colloids Surf., B, 2011, 82, 253257. 